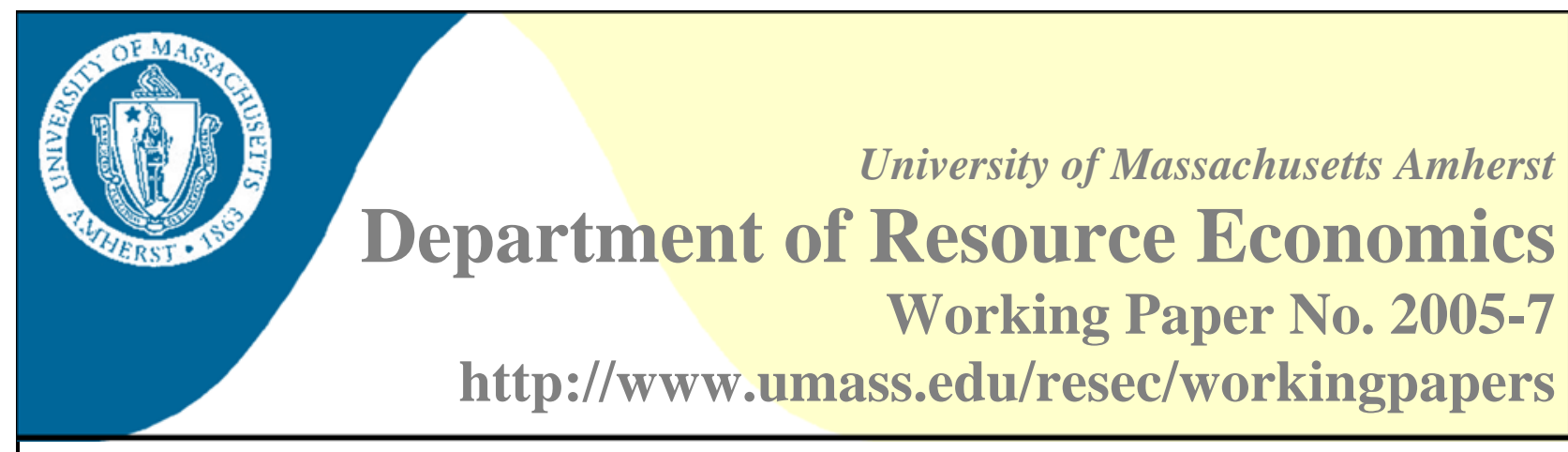

\title{
An Investigation of Voluntary Discovery and Disclosure of Environmental Violations Using Laboratory Experiments
}

\author{
James J. Murphy ${ }^{1}$ and John K. Stranlund ${ }^{2}$
}

\begin{abstract}
:
This paper uses laboratory experiments to test individual responses to policies that seek to encourage firms to voluntarily discover and disclose violations of environmental standards. We find that while it is possible to motivate a significant number of voluntary disclosures without adversely affecting environmental quality, this result is sensitive to both the fine for disclosed violations and the assumption that firms know their compliance status without cost. When firms have to expend resources to determine their compliance status, motivating a significant number of violation disclosures yields worse environmental quality. Finally, relative to conventional enforcement, disclosure polices will result in more violations being sanctioned, but fewer of these sanctions are for violations that are uncovered by the government.
\end{abstract}

Keywords: enforcement, compliance, environmental standards, self-reporting, self-auditing voluntary disclosure

JEL Classification: C91, L51, Q58

\footnotetext{
${ }^{1}$ James J. Murphy, Department of Resource Economics University of Massachusetts, Stockbridge Hall

Amherst, MA 01003

E: murphy@resecon.umass.edu P: 413-545-5716 F: 413-545-5853

${ }^{2}$ John K. Stranlund, Department of Resource Economics

University of Massachusetts, Stockbridge Hall

Amherst, MA 01003

E: stranlund@resecon.umass.edu P: 413-545-6328 F: 413-545-5853
} 


\title{
An Investigation of Voluntary Discovery and Disclosure of Environmental Violations Using Laboratory Experiments
}

\author{
JAMES J. MURPHY* \\ Department of Resource Economics \& \\ Center for Public Policy and Administration \\ University of Massachusetts-Amherst \\ JOHN K. STRANLUND \\ Department of Resource Economics \\ University of Massachusetts-Amherst
}

\section{Acknowledgements}

Primary funding for this research was provided by the U.S. EPA - Science to Achieve Results (STAR) Program grant \#R829608. Additional support was provided by the Cooperative State Research Extension, Education Service, U. S. Department of Agriculture, Massachusetts Agricultural Experiment Station, and the Department of Resource Economics under Project No. MAS00871, and by the Center for Public Policy and Administration, University of Massachusetts-Amherst. Maria Alejandra Velez and Elizabeth Gonzalez provided outstanding research assistance. We are also grateful to Jason Shogren and Jay Shimshack for useful comments on an earlier draft of this work.

\footnotetext{
"Correspondence to James J. Murphy, Department of Resource Economics, 80 Campus Center Way, 219A Stockbridge Hall, University of Massachusetts-Amherst, Amherst, MA 01003, USA. Phone: (413)545-5716, Fax: (413)545-5853, E-mail: murphy@resecon.umass.edu.
} 


\title{
An Investigation of Voluntary Discovery and Disclosure of Environmental Violations Using Laboratory Experiments
}

\begin{abstract}
This paper uses laboratory experiments to test individual responses to policies that seek to encourage firms to voluntarily discover and disclose violations of environmental standards. We find that while it is possible to motivate a significant number of voluntary disclosures without adversely affecting environmental quality, this result is sensitive to both the fine for disclosed violations and the assumption that firms know their compliance status without cost. When firms have to expend resources to determine their compliance status, motivating a significant number of violation disclosures yields worse environmental quality. Finally, relative to conventional enforcement, disclosure polices will result in more violations being sanctioned, but fewer of these sanctions are for violations that are uncovered by the government.
\end{abstract}

Keywords: enforcement, compliance, environmental standards, self-reporting, self-auditing voluntary disclosure

JEL Codes: C91, L51, Q58

\section{Introduction}

State and federal self-discovery and disclosure rules seek to encourage greater compliance with environmental regulations by reducing penalties for violations of these regulations that are voluntarily discovered and reported to authorities. For example, the EPA's Audit Policy reduces penalties "for regulated entities that voluntarily discover, promptly disclose, and expeditiously

correct noncompliance." Concurrent with the implementation of rules for voluntary discovery and disclosure of environmental violations over the last decade or so, a significant body of literature emerged that examines the conceptual properties of these rules [e.g., Malik 1993; Kaplow and Shavell 1994; Innes 1999, 2001a, 2001b; Pfaff and Sanchirico 2000]. Taken as a whole this literature is noncommittal on the question of whether voluntary disclosure policies are worthwhile complements to conventional enforcement strategies. In fact, provided that the predictions about the performance of voluntary disclosure policies hold up under empirical scrutiny, it is clear that whether these schemes are worthwhile will depend on the specifics of particular regulatory settings.

\footnotetext{
${ }^{1}$ U.S. EPA (2000). We follow the terminology used by the EPA. "Discovery" refers to costly efforts by regulated entities to discover whether they are in violation of an environmental regulation. Some also calls these actions self-audits. "Disclosure" means voluntary reporting of violations to the authorities. In the related economics literature this is usually referred to as self-reporting.
} 
Unfortunately, empirical analyses of the performance of voluntary disclosure policies are limited to just a few examinations of the effects of existing state and federal discovery and disclosure rules. For example, Stafford (2005) finds evidence that the EPA's Audit Policy and state audit policies have had a positive effect on compliance among hazardous waste facilities. Pfaff and Sanchirico (2004) examine the effects of the Audit Policy on the number and form of self-disclosed violations, and find that the policy has encouraged self-discovery and disclosure of violations, but these reported violations are minor in comparison with the violations uncovered by conventional EPA audits.

While econometric studies with non-laboratory data are critical for understanding the effectiveness of existing policies, data limitations and the inability to vary these policies in a controlled setting can preclude direct tests of theoretical predictions. Moreover, experiments provide direct control over the parameters of interest, which allows researchers to perform sensitivity analyses that may not be possible outside of the lab. Therefore, in this paper we report the results of a series of experiments designed to test fundamental hypotheses about the performance of voluntary discovery and disclosure policies. In particular, we address the following questions: How well do these policies perform in terms of motivating firms to voluntarily investigate whether they are in violation of an environmental standard and to disclose any violations they discover? How do voluntary discovery and disclosure policies affect the care that firms exercise to prevent environmental violations? Relative to conventional enforcement strategies, what are the effects of these policies on enforcement effort and environmental quality?

To address these questions we designed and conducted a series of experiments with seven treatments. Using a within-subject design, each subject participated in all seven treatments. All experiments began with a conventional enforcement model as the baseline treatment. In this treatment subjects were responsible for making a costly production decision about the level of care taken to reduce the likelihood of a violation occurring. Subjects did not incur any costs if a violation occurred; however, they were audited with a known, exogenous probability, and they were penalized if a violation was discovered. The elements of the conventional enforcement treatment were contained in the other six treatments. Each of the other treatments gave subjects the opportunity to voluntarily disclose their violations under different conditions. These treatments varied according to the penalty for voluntarily disclosed violations and whether it was costly for the subjects to determine their compliance status. 
The subjects in our experiments responded strongly to the incentive to voluntarily discover and disclose their violations. Thus, consistent with theoretical predictions, we find that offering a certain penalty for reported violations that is less than the expected penalty they would face if they chose not to report their violations motivates a significant number of voluntary disclosures. The policy significance of this is well known-relative to a conventional enforcement strategy, the government can reduce the effort it expends to detect violations, because it can focus these efforts on the subset of firms that do not disclose a violation (Malik 1993; Kaplow and Shavell 1994).

However, reducing the penalty for disclosed violations to motivate more self-reporting also reduced the care that the subjects took to avoid these violations. Thus, we find strong evidence of a tradeoff between increased violation disclosures and reduced environmental quality. This does not mean, however, that every disclosure policy results in lower environmental quality. In fact, under the condition that subjects did not have to pay to discover their compliance status, we find that it is possible to induce a significant number of violation disclosures without affecting the deterrence of a conventional enforcement strategy (Kaplow and Shavell 1994). However, increasingly complex regulations may make it difficult for firms, particularly large firms, to determine whether they are in compliance with environmental standards without undertaking a costly self-audit of their operations (Pfaff and Sanchirico 2000). Consistent with a finding by Innes (2001b), we find that when subjects had to pay to determine their compliance status, motivating a significant number of violation disclosures came at the expense of environmental quality.

Finally, we find strong support for a hypothesis of Malik's (1993) that, relative to conventional enforcement, disclosure polices will result in more violations being sanctioned, but fewer of these sanctions are for violations that are uncovered by the government. These effects could be beneficial for two reasons. First, more sanctions are levied because more violations are revealed to the government. Innes (1999) argues that the revelation of violations benefits society because their harmful effects can then be corrected. Second, Malik argues that punishing violations that are voluntarily disclosed is probably cheaper than punishing violations that the government uncovers, because punishments for disclosed violations require less evidence and are less likely to be challenged. Thus, a voluntary disclosure policy could lead to lower sanctioning costs despite the increase in the number of violations that are punished. Of course, if the costs of 
sanctioning disclosed and undisclosed violation are not that different, then a voluntary disclosure policy will yield higher sanctioning costs.

The policy significance of this work is clear. In particular, we provide empirical evidence of the fundamental tradeoffs inherent in voluntary discovery and disclosure policies. The theoretical underpinnings of this work and our experimental tests make it clear that any conclusions about the relative benefits and costs of voluntary disclosure policies will require detailed knowledge of monitoring costs, sanctioning costs, the harm caused by environmental violations, and firms' costs of internal audits to determine their compliance status. Moreover, it is likely that the question of whether disclosure policies are a worthwhile complement to regular environmental enforcement will have to be answered on a case-by-case basis.

\section{Theory and Hypotheses}

The main hypotheses of our study are drawn from a simple model of an industry composed of $n$ identical risk neutral firms. ${ }^{2}$ Each firm chooses a level of care to reduce the probability, $p$, of a violation of an environmental standard. Each has a profit function $v(p)$, with $v^{\prime}(p)>0$, and $v^{\prime \prime}(p)<0$. Under conventional enforcement of the standard, firms do not have an opportunity to disclose their violations. The government randomly audits $n_{c}<n$ firms to check for violations, so the probability that any firm will be audited is $\pi=n_{c} / n$. Uncovered violations are punished with a monetary penalty $\phi$. A risk neutral firm chooses the probability that a violation occurs to maximize its expected profit, $V(p, \pi \phi)=v(p)-p \pi \phi$. The interior choice of the probability of a violation is $p^{*}(\pi \phi)$, which is the implicit solution to $v^{\prime}(p)-\pi \phi=0$.

The main hypotheses of this work focus on the relative merits of introducing a voluntary disclosure policy to an existing conventional enforcement strategy. ${ }^{3}$ An obvious starting point is to ask whether a disclosure policy can motivate noncompliant firms to voluntarily report their violations to the government, and whether this has any affect on deterrence. Kaplow and Shavell (1993) show that as long as firms know, without cost, whether they are violating a standard, a voluntary disclosure policy can be added to a conventional enforcement strategy to motivate

2 Innes (2001b) provides a comprehensive review of the theoretical literature on voluntary discovery and disclosure policies. The model presented here is essentially the same as the one he employs to motivate his review.

${ }^{3}$ Given the risky context of our experiments and our inability to control for the risk-attitudes of the subjects, we refrain from developing hypotheses about the specific levels of accident probabilities and reporting choices. 
firms to disclose their violations without affecting the care that they take to avoid noncompliance. To demonstrate this result, suppose that firms are given the opportunity to voluntarily disclose their violations to the government, and those that do so are penalized $\phi_{d}<\phi$ automatically (the subscript $d$ indicates voluntary disclosure). It is common in the literature to assume that a firm will disclose a violation if it is at least indifferent between disclosing and facing the uncertainty of conventional enforcement. The implies that a risk neutral firm will disclose a violation if and only if the penalty for a disclosed violation is not greater than the expected penalty it faces if it fails to report the violation; that is, disclosure occurs if and only if $\phi_{d} \leq \pi \phi$. With $\phi_{d}$ set in this way, all those who are noncompliant will disclose their violations to the government. Setting $\phi_{d}=\pi \phi$ implies $p^{*}\left(\phi_{d}\right)=p^{*}(\pi \phi)$, which indicates that adding a selfdisclosure incentive does not affect a firm's choice of care or the expected number of violations in the industry, provided that firms know their compliance status without cost. We therefore have our first hypothesis:

Hypothesis 1: If firms know their compliance status without a costly self-audit, then a voluntary disclosure policy that leaves risk neutral firms indifferent between disclosing their violations and not disclosing them will not change the expected number of violations.

The assumption that firms automatically know whether they are violating the standard is a key assumption behind Hypothesis 1. Now suppose that a voluntary disclosure policy is added to conventional enforcement strategy, but that firms can only disclose their violations if they undertake a costly-audit to determine their compliance status. Innes (2001b) shows that, in this case, motivating firms to discover and disclose their violations causes deterrence (and environmental quality) to be weakened. To demonstrate this result, suppose that a firm incurs a $\operatorname{cost} c$ to discover whether it is violating the standard. As above, if a firm has discovered that it is in violation, it reports the violation to the government if $\phi_{d} \leq \pi \phi$. Assuming that this holds, if a firm does not invest in discovery, its expected payoff is the same as under conventional enforcement; that is, $V(\pi \phi)=v\left(p^{*}(\pi \phi)\right)-p^{*}(\pi \phi) \pi \phi$. If the firm invests in discovery and discloses a violation, assuming one has occurred, then it faces the certain penalty $\phi_{d}$, which induces a choice of violation probability $p^{*}\left(\phi_{d}\right)$. Thus, the firm's expected payoff when it 
discovers and voluntarily discloses a violation if one is found is $V\left(\phi_{d}\right)-c$, where $V\left(\phi_{d}\right)=v\left(p^{*}\left(\phi_{d}\right)\right)-p^{*}\left(\phi_{d}\right) \phi_{d}$. Clearly, the firm is indifferent to discovery and disclosure if $V\left(\phi_{d}\right)-c=V(\pi \phi)$. Since this requires $V\left(\phi_{d}\right)>V(\pi \phi)$, the penalty for disclosed violations must be strictly lower than the expected penalty under conventional enforcement. This implies $p^{*}\left(\phi_{d}\right)<p^{*}(\pi \phi)$, which reveals that deterrence is weakened. Thus, we have:

Hypothesis 2: If firms must incur a cost to discover their compliance status, then a voluntary disclosure policy that is designed to leave risk neutral firms indifferent to voluntary discovery and disclosure will increase the expected number of violations.

Perhaps the best-known result from the literature on voluntary disclosure policies is that they allow the government to reduce its monitoring effort (Malik 1993; Kaplow and Shavell 1994). Since the government does not need to audit those that disclose their violations, it can focus its monitoring effort on the subset of firms that do not disclose a violation. Clearly, maintaining the same level of deterrence for those who do not disclose requires fewer audits. This result holds regardless of whether firms must conduct a costly self-audit. Thus, we have:

\section{Hypothesis 3: A voluntary disclosure policy that is designed to leave risk neutral firms} indifferent to disclosing their violations will reduce the number of audits that are required to maintain the same level of deterrence for those that do not disclose their violations.

While we expect that adding a voluntary disclosure policy to a conventional enforcement strategy will allow the government to reduce its monitoring effort, we also expect that more violations will be revealed (either voluntarily disclosed or uncovered by an audit) to the government and sanctioned. If firms do not have to pay to determine their compliance status, Hypothesis 1 asserts that the expected number of violations will be unchanged. However, the violations that are disclosed are revealed and sanctioned with certainty, whereas without the disclosure opportunity these violations would only be revealed and sanctioned with the probability of an audit. This move toward more sanctions is reinforced when firms must audit 
themselves to determine their compliance status, simply because deterrence is weaker and the expected number of violations increases (Hypothesis 2).

This effect of a disclosure policy on revealed violations and sanctions is intriguing because it is not clear whether this is an advantage or a disadvantage. Given a fixed number of violations, that more of them are revealed is probably in society's best interest. Innes (1999) has argued that when firms are required to correct the harm caused by their violations, voluntary disclosure policies result in improved environmental quality because more violations are corrected.

On the other hand, sanctioning firms is likely to be costly. Kaplow and Shavell (1994) note that, since more firms are sanctioned under a disclosure rule, it is possible that enforcement costs could actually increase if the additional costs of more sanctions outweigh the reduction in monitoring costs. However, a voluntary disclosure policy induces a shift from penalizing violations that are uncovered by the government to penalizing voluntarily disclosed violationsalthough more violations are punished, fewer of these are violations that are uncovered by the government. Malik (1993) argues that a voluntary disclosure policy may decrease sanctioning costs, because punishing disclosed violations is probably cheaper than punishing violations that the government uncovers. A firm that voluntarily discloses a violation is essentially admitting liability for being noncompliant. This admission can reduce the burden on the government to produce sufficient evidence for a finding of liability. Moreover, a firm that voluntarily admits liability is less likely to engage in costly efforts to challenge or otherwise avoid the imposition of a penalty.

To examine the effects of a voluntary disclosure policy on the number of sanctions levied on disclosed and undisclosed violations we have our final hypotheses:

Hypothesis 4: A voluntary disclosure policy that is designed to leave risk neutral firms indifferent to disclosing their violations will increase the expected number of total sanctions.

Hypothesis 5: A voluntary disclosure policy that is designed to leave risk neutral firms indifferent to disclosing their violations will reduce the expected number of sanctions that are levied on undisclosed violations. 


\section{Experimental Design}

The experiments were designed to test the hypotheses presented in the previous section and were conducted in a computer lab using software specifically developed for this research. In all treatments, subjects were responsible for making a production decision that yielded earnings, $v$. When they produced, there was a probability, $p$, that an accident would occur. ${ }^{4}$ Subjects could reduce the likelihood of an accident, but this was costly in terms of foregone production earnings, in particular, $v(p)=3.60-(0.55 /(0.30+p))$. The computer screen presented each subject with a table that displayed all the possible accident probability/production earning combinations in 5\% increments, constrained between 5\% and 95\%. Subjects did not incur any costs if an accident occurred; however, they were audited with a known, exogenous probability, and they incurred a fine if an accident was discovered.

Table 1 summarizes the experimental design. The Conventional Enforcement treatment (CE) formed the baseline; the remaining six treatments built upon $\mathrm{CE}$ such that all features of $\mathrm{CE}$ were common throughout the experiment. Under the CE treatment, each subject was audited with probability $\pi=60 \%$. If an accident occurred and was uncovered through an audit, then the subject incurred a fine $\phi=\$ 2.50$. Subjects in this treatment did not have an opportunity to voluntarily disclose accidents.

The middle column of Table 1 contains our Voluntary Disclosure Only treatments: D-H, D-I, and D-L. In these treatments, subjects knew automatically and without cost whether an accident occurred. These treatments were identical to the CE treatment, except that subjects had the option to voluntarily disclose whether an accident occurred. If a subject chose not to disclose an accident, then she faced the identical enforcement strategy as CE (60\% audit probability, $\$ 2.50$ fine). However, if she chose to voluntarily disclose an accident, then she automatically paid a reduced fine, $\phi_{d}$. The level of this fine is the distinguishing factor among the D-H, D-I and D-L treatments and is shown in parentheses next to the treatment labels in Table 1.

In treatment D-I, the certain penalty for a voluntarily disclosed violation was set at $\phi_{d}=\$ 1.50$ to make a risk-neutral subject indifferent between disclosing an accident if one occurred and facing the uncertainty of the conventional enforcement strategy. Note that this

\footnotetext{
4 Although our interest is in the effects of voluntary disclosure policies on the care taken to prevent environmental violations and the reporting of any violations that do occur, we framed the experiments as a production decision in which subjects chose the probability of an unspecified accident.
} 
penalty equals the expected penalty under conventional enforcement, $\pi \phi=\phi_{d}=\$ 1.50$. Earlier, we noted that the theoretical literature typically assumes that a risk-neutral agent will choose to voluntarily report if it is at least indifferent between disclosing a violation and facing the uncertainty of conventional enforcement. Clearly, in an experimental setting we do not expect that all subjects are risk neutral, or that they would always choose to report when indifferent between reporting and not. Therefore, to examine the responsiveness of the subjects to the voluntary disclosure incentive, we chose a higher disclosure penalty of $\$ 2.35$ for the D-H treatment and a lower disclosure penalty of $\$ 0.97$ for the D-L treatment.

The final column of Table 1 contains our Voluntary Disclosure with Costly Discovery treatments: CD-H, CD-I, and CD-L. These treatments were the same as the Voluntary Disclosure Only treatments, except that subjects did not know whether an accident occurred unless they paid $\$ 0.20$ to find out. Those who chose not to pay the $\$ 0.20$ cost of self-discovery could not voluntarily disclose an accident and therefore faced the identical enforcement strategy as CE. Like the Voluntary Disclosure Only treatments, the Costly Discovery treatments varied according to the penalty for disclosed accidents. In treatment CD-I, the certain penalty for a disclosed violation was set at $\phi_{d}=\$ 0.97$. This is the disclosure penalty that would make a risk neutral subject indifferent between discovery and disclosing an accident and facing the conventional enforcement strategy. Notice that the penalty for a disclosed violation in the CD-I treatment is lower than in the D-I treatment in order to motivate the subjects to invest in selfdiscovery. As with the Voluntary Disclosure Only treatments, we chose a higher disclosure penalty for CD-H and a lower penalty for CD-L to examine the responsiveness of subjects to the disclosure incentive.

For the six treatments that included the option to voluntarily disclose an accident, we used the strategy method to ensure that we had an observation about a subject's reporting decision regardless of whether an accident occurred. Before it was revealed whether an accident occurred, subjects had to decide whether they would commit to voluntarily disclosing an accident if one occurred, or face the uncertainty of random audits and potential penalties under conventional enforcement. Conceptually, since the disclosure decision was not costly, forcing subjects to commit to this decision at the outset should not affect their behavior.

A total of 180 students were recruited from the student population at the University of Massachusetts, Amherst. Subjects were paid \$5 for agreeing to participate and showing up on 
time, and were then given an opportunity to earn additional money in the experiment. These additional earnings ranged between $\$ 10.55$ and $\$ 18.27$, with a mean of $\$ 14.88(\sigma=1.49)$. Earnings were paid in cash at the end of each experiment. Each experiment lasted about an hour and a half. Subjects were given a copy of the instructions that the experimenter then read aloud. ${ }^{5}$ The experimenter used an overhead projector to demonstrate the software while the subjects performed the same tasks on their individual computers. It took about 30 minutes to complete the instructions and answer any questions. The same experimenter conducted all sessions.

Every subject participated in all seven treatments, starting with Conventional Enforcement as the baseline. The remaining six treatments were presented in one of six sequences using a Latin Square design to control for possible order effects; 30 subjects participated in each of the six sequences. The sequences of treatments are provided in Table 2. Within a sequence (i.e., a row in Table 2) there were seven stages, one for each treatment. A stage consisted of three practice rounds, followed by a "real money" round. The parameters for the practice and real rounds were the same; data from practice rounds were discarded. The Latin Square was constructed such that each treatment appears once in each sequence, once in each stage (i.e., a column in Table 2), and each treatment precedes and follows every other treatment one time.

\section{Results}

\subsection{Model specification}

To formally test our hypotheses, Table 3 presents the results of three linear random effects models that control for repeated measures (multiple observations from a single subject). The dependent variables in the three models are the probabilities of an accident (ProbAccident), audit (ProbAudit) and fine (ProbFine), respectively. The ProbAccident variable is the explicit choice made by each subject. The ProbAudit and ProbFine variables are calculated from the individual's choice of accident probability and reporting decision (Disclosed) as shown in equations [1] and [2] below:

\footnotetext{
5 Instructions are available upon request.
} 
[1] ProbFine $= \begin{cases}\text { ProbAccident } & \text { if Disclosed }=1(\mathrm{Yes}) \\ \text { ProbAccident } \times 60 \% & \text { if Disclosed }=0(\mathrm{No})\end{cases}$

[2] ProbAudit $= \begin{cases}(100-\text { ProbAccident }) \times 60 \% & \text { if Disclosed }=1(\mathrm{Yes}) \\ 60 \% & \text { if Disclosed }=0(\mathrm{No})\end{cases}$

Under the CE treatment, ProbFine and ProbAudit are identical to Disclosed $=$ No in the above equations because choosing not to disclose is identical to choosing to face a conventional enforcement strategy. With a voluntary disclosure policy, all who disclose an accident will automatically incur the reduced fine. Note, however, that for those who choose to disclose, ProbFine is not equal to one. This is an artifact of having subjects commit to a disclosure decision before knowing whether an accident occurred. For those who do commit to disclosing an accident, it is possible that an accident will not occur in which case they have nothing to report and are not fined. If an accident does occur, it will be reported and the disclosure penalty is automatically applied. Hence, the probability of a fine is simply the probability that an accident will occur.

Using similar reasoning, the audit probability for those who disclose is not zero in equation [2]. Recall that with a voluntary disclosure policy those who disclose an accident need not be audited. However, from the regulator's perspective, the absence of a report could mean either there was no accident (and hence nothing to report) or there was an accident that was not disclosed. Therefore, it is possible that an individual who commits to disclosing an accident could be audited if it turns out that an accident did not occur. We are effectively assuming that had these subjects known that an accident did not occur prior to the reporting decision, then they would have truthfully chosen not to report an accident and may have been audited but not fined. We preclude the possibility that a subject would falsely report that an accident occurred.

All the explanatory variables in Table 3 are dummy variables. The constant references the conventional enforcement treatment CE. D-H, D-I, and D-L refer to the three Voluntary Disclosure Only treatments; CD-H, CD-I, and CD-L refer to the three Costly Discovery treatments. These variables can be interpreted as the change from CE, the omitted dummy variable, for those who choose not to disclose. The interaction of these variables with Disclosed, which equals one if a subject committed to reporting an accident, represents the difference 
between those who do and do not disclose in a given treatment. LagFined is a dummy variable that equals one if a subject incurred a fine in the previous real money stage. Since stage 1 for all subjects was CE, there is no lag. To preserve the observations from this treatment, we assume that LagFined $=0$ for CE.

Using the regression models in Table 3, we calculated the estimated accident probabilities, and the expected numbers of accidents, fines, and audits; these are presented in Table 4 . The first column presents the estimated accident probabilities for disclosers and non-disclosers for each treatment. The next column, N, is the number of subjects who selected each disclosure option. By combining this information, we calculated the expected number of accidents. Using a similar approach, we used the Audit Probability and Fine Probability models in Table 3 to calculate the expected numbers of audits and fines.

\subsection{Hypothesis tests}

Before discussing our hypothesis tests, it is worth noting that, as expected, the observed outcomes do not match specific predictions about accident probabilities and reporting choices based on a model of risk neutral, expected payoff-maximizing agents. Our estimated accident probabilities tend to be higher than what a risk-neutral subject would be expected to choose. Furthermore, no risk neutral subject would choose to disclose an accident in the D-H and CD-H treatments, yet a non-trivial minority of subjects did so. Similarly, every risk neutral subject would choose to disclose their accidents in the D-L and CD-L treatments, but a non-trivial minority of subjects chose not to do so.

The models in Table 3 were used to construct the hypothesis tests. <see reviewer's appendix for how these tests were constructed $>$. First consider the impacts of voluntary disclosure on the expected number of accidents in D-I and CD-I relative to conventional enforcement. Both the DI and CD-I treatments were parameterized such that a risk neutral subject would be indifferent between disclosing and not disclosing an accident. When self-discovery is costless, as in D-I, there should be no change in the expected number of accidents relative to conventional enforcement. Indeed, this is precisely what we observe. Table 4 shows that the expected number of accidents under CE is 91.66 vs. 91.19 under D-I. Consistent with Hypothesis 1, we fail to reject the hypothesis that these are equal using the Accident Probability model of Table 3 to construct a Wald chi-squared test $(p=0.89)$. Thus, it appears that it is possible to add a 
disclosure opportunity to a conventional enforcement strategy without affecting deterrence - at least as long as there are no discovery costs.

However, when it is costly for a firm to engage in self-discovery, as in CD-I, the penalty for disclosed accidents (\$0.97) is lower than the expected penalty under conventional enforcement (\$1.50), which weakens deterrence and should lead to an increase in the expected number of accidents. As hypothesized (Hypothesis 2), the expected number of accidents in CD-I (98.51) exceeds that of conventional enforcement and this difference is statistically significant ( $p=$ $0.05)$.

The main conceptual benefit of a voluntary disclosure policy is that those who voluntarily report an accident do not need to be audited; therefore the government can maintain the same level of deterrence for those that do not disclose, but with fewer audits (Hypothesis 3). From Table 4, the expected number of audits for the D-I treatment is 82.07, and for CD-I the expected number of audits is 72.5. Using the Audit Probability model in Table 3, both of these are significantly below the 108 audits under CE ( $p=0.00$ in both cases).

Although these results indicate that the regulator would benefit from reduced monitoring costs when the disclosure penalty is set such that firms are indifferent between disclosing their violations and not doing so, Hypothesis 4 suggest that the expected total number of fines, and possibly sanctioning costs, could increase. In Table 4, the total number of expected fines is 72.06 for D-I and 82.23 for CD-I, both of which exceed the 54.99 expected number of fines under CE. The Fine Probability model is used to determine that these differences are statistically significant $(p=0.00$ in both cases).

If the costs of sanctioning disclosed violations are lower than the costs of sanctioning undisclosed violations, the effect of the increase in the number of fines on total sanctioning costs will depend upon the distribution of these fines between disclosed and undisclosed accidents. Although Hypothesis 4 suggests that the total number of fines will be greater than under conventional enforcement, Hypothesis 5 suggests that the expected number of the potentially more costly fines for undisclosed violations will be smaller. Our results support this hypothesis. Of the 72.06 expected fines under D-I, only 29.34 are for accidents that are uncovered by an audit. Similarly, under CD-I, only 23.29 of the 82.83 expected fines are for undisclosed accidents. Both of these are a statistically significant reduction from the 54.99 expected fines under CE $(p=0.00)$. 


\subsection{Sensitivity analysis}

Our hypotheses, and hence, the discussion thus far has centered on the two treatments that were parameterized such that risk neutral agents would be indifferent to whether to disclose an accident. To test the sensitivity of our results to the incentive for voluntary disclosure, we varied the reduced penalty for voluntarily reported accidents. In the six Disclosure Only and Costly Discovery treatments, those who chose not to report an accident faced the same $60 \%$ audit probability and $\$ 2.50$ fine as in the Conventional Enforcement treatment. Thus, we expect that the choice of accident probability for non-disclosers should remain the same as under the conventional enforcement treatment. This implies that in the Accident Probability model in Table 3, the coefficients for the six Disclosure Only and Costly Discovery treatments should not be statistically significant. Contrary to this hypothesis, in three cases the coefficients are significant (D-H, CD-H and CD-I). However, in all six cases, the coefficients are negative and relatively small. This could suggest that there is a small framing effect associated with the introduction of the option for voluntary accident disclosure that induces subjects that choose not to disclose to make small reductions in their accident probabilities.

More significantly, there is strong evidence to indicate that the decision to report an accident is accompanied by a potentially substantial decrease in the care that individuals take to prevent accidents. Consider the coefficients in the Accident Probability Model in Table 3 that interact the treatment with the decision to disclose an accident. Only for the $\mathrm{D}-\mathrm{H}$ treatment is there no statistically significant difference in the accident probability between disclosers and nondisclosers (the coefficient for Disclosed $\times \mathrm{D}-\mathrm{H}$ is small and not statistically significant). In all of the other treatments, the accident probabilities chosen by those who disclose their accidents are significantly higher than the accident probabilities chosen by non-disclosers. Moreover, the accident probabilities of disclosers increases rather rapidly as the penalty for disclosed accidents is reduced in both the Disclosure Only and Costly Discovery treatments. Since the number of subjects who choose to disclose their accidents also increases as the disclosure penalty is reduced, the expected number of accidents of those who disclose increases quickly as the disclosure penalty is reduced. Note from Table 4 that the expected number of disclosed accidents increases from 17.88 to 42.58 and then to 80.25 as the penalty for disclosed accidents is reduced in the Disclosure Only treatments. A similar pattern occurs in the Costly Discovery treatments. 
Largely because the number of subjects who choose to disclose their accidents increases and they choose higher accident probabilities as the disclosure penalty is reduced, the expected total number of accidents also increases as this penalty is reduced. From Table 4, the expected number of accidents increases in the Disclosure Only treatments from 82.93 to 91.19 and then 111.64. A test of the hypothesis that these values are jointly equal is rejected at $p=0.00$. This pattern and level of statistical significance hold for the Costly Discovery treatments as well.

While the expected number of accidents increases as the disclosure penalty is reduced, the expected number of audits falls - from 95.81 to 82.07 and then to 61.3 for the Disclosure Only treatments and similarly for the Costly Discovery treatments. These reductions in the number of audits are both highly significant (joint tests of the hypotheses that the expected numbers of audits are equal as the disclosure penalty is reduced are rejected at $p=0.00$ for both sets of treatments). Our results clearly suggest an important trade-off inherent in voluntary discovery and disclosure policies: reducing the penalty that firms pay if they voluntarily disclose a violation is effective at inducing more of them to report their violations, thereby conserving monitoring effort, but these lower penalties also provide an incentive for firms to exercise less care in avoiding violations.

Of course, whether the reduction in monitoring effort results in a reduction in total enforcement costs also depends upon the impact on sanctioning costs. The results in Table 4 show that lowering the penalty for disclosed violations increases the total number of fines (from 57.96 to 72.06 to 98.17 for D-H, D-I and D-L respectively; a similar pattern holds for the Costly Discovery treatments). However, fewer of these are the potentially more costly fines associated with undisclosed accidents. Thus, although lower disclosure penalties led to more penalties being levied, fewer penalties were levied on undisclosed violations. Clearly, whether total enforcement costs fall with a greater incentive for voluntary discovery and disclosure depends on the relative costs of monitoring and sanctioning disclosed and undisclosed violations.

\section{Conclusion}

A key message of our study is that while it is possible to motivate a significant number of voluntary disclosures without adversely affecting environmental quality, this result is sensitive to two important assumptions: (1) the certain penalty for reported violations must equal the expected penalty firms would face if they chose not to report their violations, and (2) firms must 
perfectly know their compliance status without cost. When these two conditions are satisfied, society can benefit because the number of violations is unchanged, yet more of these violations are made known to the government (either voluntarily or through random audits). This increased knowledge about violations means that more violations see the light of day, which can be beneficial because then the harmful effects of the violations can be addressed. However, if either of these two conditions is not met, then the benefits of voluntary disclosure policies are likely to be offset by a reduction in environmental quality.

The reduced fine necessary to induce voluntary disclosure can loosely be viewed as the "price" that society pays for the revelation of privately held information about a firm's environmental performance. Without this disclosure incentive, society must engage in the costly process of auditing firms and sanctioning violations. Whether a voluntary disclosure policy is more cost effective than increased conventional enforcement as means of generating increased knowledge about violations is an empirical question that this research cannot address. We note that in our data, consistent with theoretical predictions, the total amount of fines collected under conventional enforcement is almost identical to that in our D-I treatment. Therefore, in comparing D-I to conventional enforcement, we observe no change in environmental quality or the total fines collected, but observe increased discovery of violations by the regulator even though monitoring effort has been reduced. The net effect on sanctioning costs is ambiguous, but these are likely to decrease if the costs of sanctioning voluntarily disclosed violations are lower than that of undisclosed violations discovered through an audit.

In reality, however, many firms will have to undertake a costly self-audit to uncover this information. For example, Pfaff and Sanchirico (2000) mention that Occidental Petroleum had to monitor 140,000 points that generated 4 to 7 million observations in just four of their plants. In this case, we found that motivating subjects to invest in discovering their compliance status and to report any violations they find is associated with lower environmental quality. Moreover, we find that reducing the penalty for disclosed violations to motivate more self-reporting also reduces the care taken to avoid these violations - which increases the frequency of violations and reduces overall environmental quality.

While we have motivated our study by focusing on voluntary discovery and disclosure policies to support compliance with environmental regulations, our results apply much more broadly. Many environmental statutes require that firms report their compliance status to 
regulators. Although our experiments, and most of the literature on self-reporting, have focused on voluntary reporting, the tradeoffs that we highlight will also manifest themselves when reporting is mandatory. In addition, the use of disclosure policies extends beyond environmental policies to regulations concerning occupational health and safety, product safety, and federal sentencing guidelines (Kaplow and Shavell 1994; Innes 2001b). Our results apply to these contexts as well.

Our design and results should provide baselines for extensions of the models of voluntary disclosure that we have not examined. For example, our experimental framework can easily be adapted to examine Innes' (1999 and 2001a) claims that there are additional benefits to voluntary discovery and disclosure policies when firms are required to undertake costly remediation (e.g., clean-up of spills), or when they are able to engage in costly efforts to avoid government detection and punishment of their violations. Likewise, the claims of several authors that selfdiscovery and disclosure rules might not be as effective as hoped because firms fear that the information they discover might improve the government's own monitoring efforts (Pfaff and Sanchirico 2000, Mishra et al. 1997) can and should be examined within our framework.

Our finding that a significant minority of subjects chose to disclose their accidents when faced with a high disclosure penalty, and another minority of subjects chose to not disclose when faced with a low disclosure penalty suggests that our subject pool may have included a mix of risk-averse, risk-neutral, and risk-loving individuals. Unfortunately, we hesitate to attribute any our results to a particular pattern of risk preferences because of our inability to control for these preferences. While our study could benefit from information about subjects' risk preferences, unfortunately there is no consensus about how to elicit these preferences. Instruments such as that presented by Holt and Laury (2002) may be useful, but there is evidence that risk preferences may be domain specific and not stable across institutions (Isaac and James, 2000). Therefore it is unclear whether risk preferences elicited with the Holt Laury mechanism would be robust in predicting behavior in other settings. We believe that this is an important area for future experimental research on enforcement and compliance behavior.

Finally, while we have highlighted some of the essential tradeoffs inherent in voluntary discovery and disclosure policies, a full welfare analysis of the effects of voluntary disclosure policies is beyond the scope of this research. In general, it appears that there is little theoretical or empirical justification to warrant general support for, or opposition to, voluntary discovery 
and disclosure policies. It is clear, though, that any conclusion about the benefits and costs of voluntary disclosure policies will require detailed knowledge of the harm caused by environmental violations, the costs of monitoring firms and sanctioning violations, as well as firms' costs of auditing themselves to determine their compliance status. It appears highly probable that whether disclosure policies are worthwhile will depend on the specifics of particular regulatory settings. 


\section{References}

Holt, C.A. and S.K. Laury. 2002. "Risk Aversion and Incentive Effects." American Economic Review 92(5): 1644-55.

Innes, Robert. 1999. "Remediation and Self-Reporting in Optimal Law Enforcement." Journal of Public Economics 72:379-393.

Innes, Robert. 2001a. "Violator Avoidance Activities and Self-Reporting in Optimal Law Enforcement." Journal of Law, Economics, and Organization, 17(1): 239-256.

Innes, Robert. 2001b. "Self Enforcement of Environmental Law." In The Law \& Economics of the Environment. Anthony Heyes (ed.). Edward Elgar, Cheltenham, England.

Isaac, R.M. and James, D. (2000). “Just Who Are You Calling Risk Averse?” Journal of Risk and Uncertainty, 20(2):177-187.

Kaplow, Louis and Steven Shavell. 1994. "Optimal Law Enforcement with Self-Reporting of Behavior.” Journal of Political Economy 103(3): 583-606.

Malik, Arun. 1993. "Self-Reporting and the Design of Policies for Regulating Stochastic Pollution." Journal of Environmental Economics and Management 24: 241-257.

Mishra, Birendra K., D. Paul Newman and Christopher H. Stinson 1997. "Environmental Regulations and Incentives for Compliance Audits." Journal of Accounting and Public Policy, 16:187-214.

Pfaff, Alexander and Chris W. Sanchirico. 2000. "Environmental Self-Auditing: Setting the Proper Incentives for Discovery and Correction of Environmental Harm." Journal of Law, Economics \& Organization 16(1): 189-208.

Pfaff, Alexander and Chris W. Sanchirico. 2004. "Big Field, Small Potatoes: An Empirical Assessment of EPA's Self-Audit Policy." Journal of Policy Analysis \& Management 23(3): 415-432.

Stafford, Sarah L. 2005. "Does Self-Policing Help the Environment? EPA's Audit Policy and Hazardous Waste Compliance.” Forthcoming in Vermont Journal of Environmental Law.

U.S. Environmental Protection Agency. 2000. "Incentive for Self-Policing: Discovery, Disclosure, Correction and Prevention of Violations." Federal Register 65(70): 1961819627. Available at http://www.epa.gov/compliance/incentives/auditing/auditpolicy.html 
Table 1: Experimental Design

\begin{tabular}{ccc}
\hline $\begin{array}{c}\text { Conventional } \\
\text { Enforcement }\end{array}$ & $\begin{array}{c}\text { Voluntary } \\
\text { Disclosure Only }\end{array}$ & $\begin{array}{c}\text { Voluntary Disclosure } \\
\text { with Costly Discovery }\end{array}$ \\
\hline & D-H $(2.35)$ & CD-H $(1.50)$ \\
CE & D-I $(1.50)$ & CD-I $(0.97)$ \\
& D-L $(0.97)$ & CD-L $(0.60)$ \\
\hline
\end{tabular}

The conventional enforcement penalty in all treatments is 2.50 . The reduced penalty, $\phi_{d}$, for voluntary disclosure is shown in parentheses.

Table 2: Sequence of Treatments Using a Latin Square

\begin{tabular}{cccccccc}
\hline & \multicolumn{7}{c}{ Stage } \\
\cline { 2 - 8 } Sequence ID & $\mathbf{1}$ & $\mathbf{2}$ & $\mathbf{3}$ & $\mathbf{4}$ & $\mathbf{5}$ & $\mathbf{6}$ & $\mathbf{7}$ \\
\hline $\mathbf{A}$ & $\mathrm{CE}$ & D-H & D-I & CD-L & D-L & CD-I & CD-H \\
$\mathbf{B}$ & $\mathrm{CE}$ & D-I & D-L & D-H & CD-H & CD-L & CD-I \\
$\mathbf{C}$ & $\mathrm{CE}$ & D-L & CD-H & D-I & CD-I & D-H & CD-L \\
$\mathbf{D}$ & CE & CD-H & CD-I & D-L & CD-L & D-I & D-H \\
$\mathbf{E}$ & CE & CD-I & CD-L & CD-H & D-H & D-L & D-I \\
$\mathbf{F}$ & CE & CD-L & D-H & CD-I & D-I & CD-H & D-L \\
\hline
\end{tabular}


Table 3: Estimation Results Using Linear Random Effects Models

\begin{tabular}{|c|c|c|c|c|c|c|}
\hline & \multicolumn{2}{|c|}{ Accident Probability } & \multicolumn{2}{|c|}{ Audit Probability } & \multicolumn{2}{|c|}{ Fine Probability } \\
\hline & Coef. & Std. Err. & Coef. & Std. Err. & Coef. & Std. Err. \\
\hline Constant & $50.92 * * *$ & 1.88 & $60.00 * * *$ & 0.77 & $30.55 * * *$ & 1.53 \\
\hline LagFined & $-2.35 * *$ & 1.15 & 0.84 & 0.57 & $-2.05 * *$ & 0.98 \\
\hline D-H & $-5.11 * *$ & 2.10 & -0.69 & 1.04 & -2.55 & 1.78 \\
\hline D-I & -2.80 & 2.31 & -0.24 & 1.14 & -1.50 & 1.96 \\
\hline D-L & -1.10 & 2.71 & 0.68 & 1.33 & -1.16 & 2.30 \\
\hline CD-H & $-7.37 * * *$ & 2.23 & -0.41 & 1.10 & $-4.12 * *$ & 1.89 \\
\hline CD-I & $-6.07 * * *$ & 2.46 & -0.21 & 1.21 & $-3.47 *$ & 2.09 \\
\hline CD-L & -2.69 & 3.10 & 0.28 & 1.52 & -1.80 & 2.63 \\
\hline Disclosed $\times$ D-H & 1.23 & 3.47 & $-28.80 * * *$ & 1.70 & $19.89 * * *$ & 2.94 \\
\hline Disclosed $\times$ D-I & $5.78 * *$ & 2.86 & $-32.27 * * *$ & 1.40 & $25.02 * * *$ & 2.42 \\
\hline Disclosed $\times$ D-L & $18.77 * * *$ & 2.97 & $-40.96 * * *$ & 1.46 & $38.69 * * *$ & 2.52 \\
\hline Disclosed $\times$ CD-H & $11.84 * * *$ & 2.94 & $-32.84 * * *$ & 1.44 & $29.01 * * *$ & 2.49 \\
\hline Disclosed $\times$ CD-I & $18.91 * * *$ & 2.84 & $-37.36 * * *$ & 1.39 & $36.26 * * *$ & 2.41 \\
\hline Disclosed $\times$ CD-L & $23.82 * * *$ & 3.25 & $-42.88 * * *$ & 1.59 & $42.92 * * *$ & 2.75 \\
\hline
\end{tabular}

Asterisks reflect $\mathrm{p}$-values: $* p \leq 0.10 ; * * p \leq 0.05 ; * * * p \leq 0.01 . \mathrm{N}=1260$ (7 observations from each of 180 subjects). Wald chi-squared tests indicate that each of the models is highly significant $(p=0.00)$. 
Table 4: Estimated Accident Probabilities, and Expected Numbers of Accidents, and Enforcement Actions

\begin{tabular}{|c|c|c|c|c|c|}
\hline $\begin{array}{c}\text { Treatment } \\
\text { (Disclosure Penalty) }\end{array}$ & $\begin{array}{c}\text { Estimated } \\
\text { Accident } \\
\text { Probability }^{\text {a }}\end{array}$ & $\mathbf{N}$ & $\begin{array}{c}\text { Expected } \\
\text { Number of } \\
\text { Accidents }\end{array}$ & $\begin{array}{c}\text { Expected } \\
\text { Number of } \\
\text { Audits }^{c}\end{array}$ & $\begin{array}{c}\text { Expected } \\
\text { Number of } \\
\text { Fines }\end{array}$ \\
\hline $\mathbf{C E}$ & $50.92 \%$ & 180 & 91.66 & 108 & 54.99 \\
\hline D-H (2.35) & & 180 & 82.93 & 95.8 & 57.96 \\
\hline Disclosed & $47.04 \%$ & 38 & 17.88 & & 18.20 \\
\hline Undisclosed & $45.81 \%$ & 142 & 65.05 & & 39.76 \\
\hline D-I (1.50) & & 180 & 91.19 & 82.1 & 72.06 \\
\hline Disclosed & $53.90 \%$ & 79 & 42.58 & & 42.72 \\
\hline Undisclosed & $48.12 \%$ & 101 & 48.60 & & 29.34 \\
\hline D-L (0.97) & & 180 & 111.64 & 61.3 & 98.17 \\
\hline Disclosed & $68.59 \%$ & 117 & 80.25 & & 79.65 \\
\hline Undisclosed & $49.82 \%$ & 63 & 31.39 & & 18.52 \\
\hline CD-H (1.5) & & 180 & 86.21 & 85.6 & 66.72 \\
\hline Disclosed & $55.39 \%$ & 66 & 36.56 & & 36.59 \\
\hline Undisclosed & $43.55 \%$ & 114 & 49.65 & & 30.13 \\
\hline CD-I (0.97) & & 180 & 98.51 & 72.5 & 82.83 \\
\hline Disclosed & $63.76 \%$ & 94 & 59.93 & & 59.54 \\
\hline Undisclosed & $44.85 \%$ & 86 & 38.57 & & 23.29 \\
\hline CD-L (0.60) & & 180 & 118.73 & 51.0 & 109.26 \\
\hline Disclosed & $72.05 \%$ & 134 & 96.55 & & 96.04 \\
\hline Undisclosed & $48.23 \%$ & 46 & 22.19 & & 13.23 \\
\hline
\end{tabular}

${ }^{\text {a }}$ Calculated from the Accident Probability model in Table 3, assuming LagFined $=0$.

b For each disclosure decision, Expected Number of Accidents $=$ Estimated Accident Probability $\times$ N. Total Expected Number of Accidents is the sum of disclosed and undisclosed accidents.

c Calculated from the Audit Probability model in Table 3 using the same approach as the expected number of accidents.

${ }^{d}$ Calculated from the Fine Probability model in Table 3 using the same approach as the expected number of accidents. 


\section{REVIEWER'S APPENDIX}

\section{CONSTRUCTION AND RESULTS OF HYPOTHESIS TESTS}

\begin{tabular}{|l|c|c|}
\hline $\begin{array}{l}\text { Hypothesis Tests About Expected Number of Accidents } \\
\text { (Using the Accident Probability Model in Table 3) }\end{array}$ & $\chi^{\mathbf{2}(\mathbf{1})}$ & $\boldsymbol{p}$ \\
\hline $\begin{array}{l}\text { Hyp 1. DI (undisclosed + disclosed })=\text { CE } \\
101 *(\text { Constant }+ \text { DI })+79 *(\text { Constant }+ \text { DI }+ \text { DisclosedxDI })\end{array}$ & 0.02 & 0.89 \\
$=180 *($ Constant $)$ & & \\
\hline Hyp 2. CDI (undisclosed + disclosed $)>$ CE & & \\
$86 *($ Constant + CDI $)+94 *($ Constant + CDI + DisclosedxCDI $)$ & 3.8 & 0.05 \\
$=180 *($ Constant $)$ & & \\
\hline
\end{tabular}

For each treatment, we can derive the expected number of accidents within the data by multiplying the estimated accident probability given a reporting choice by the observed number of subjects selecting each reporting choice. We then use this to construct the appropriate test statistic for each hypothesis. Below are the details for how Hypothesis 1 was constructed using the Accident Probability model in Table 3; all the other hypotheses are constructed using a similar approach.

Hypothesis 1 compares the expected number of accidents in the CE and DI treatments. There are a total of 180 subjects. In the CE treatment, subjects do not have a disclosure option. The constant (50.92) is the estimated accident probability for the CE treatment. Multiplying the constant by 180 yields the expected number of accidents for the CE treatment.

Of the 180 total subjects, 101 chose not to disclose an accident in D-I, while 79 committed to disclosure. The estimated probability of an accident given the choice not to disclose is the constant + CDI, which when multiplied by 101 yields the expected number of accidents for those choosing not to disclose. Similarly, the constant + CDI + Disclosed $\times$ CDI is the estimated accident probability given the commitment to disclose an accident; multiplying this by the 79 subjects who chose to report yields the expected number of accidents for this subset.

Hence, $101 *($ Constant + DI $)+79 *($ Constant + DI + DisclosedxDI $)$ is the expected number of accidents in the DI treatment (combining disclosed and undisclosed accidents), and $180^{*}$ (Constant) is the expected number of accidents in the CE treatment. We use a Wald chisquared test to determine whether there is a statistically significant difference in the expected number of accidents between the two treatments. 


\begin{tabular}{|l|c|c|}
\hline $\begin{array}{l}\text { Hypothesis Tests About Expected Number of Audits } \\
\text { (Using the Audit Probability Model in Table 3) }\end{array}$ & $\chi^{2}(\mathbf{1})$ & $\boldsymbol{p}$ \\
\hline $\begin{array}{l}\text { Hyp 3a. DI (undisclosed + disclosed }<\text { CE } \\
\quad 101 *(\text { Constant }+ \text { DI })+79 *(\text { Constant }+ \text { DI }+ \text { DisclosedxDI })\end{array}$ & 228.3 & 0.00 \\
$=180 *($ Constant $)$ & & \\
\hline $\begin{array}{l}\text { Hyp 3b. CDI (undisclosed + disclosed })<\text { CE } \\
\quad 86 *(\text { Constant }+ \text { CDI })+94 *(\text { Constant }+ \text { CDI }+ \text { DisclosedxCDI })\end{array}$ & 417.5 & 0.00 \\
$=180 *($ Constant $)$ & & \\
\hline
\end{tabular}

\begin{tabular}{|l|c|c|}
\hline $\begin{array}{l}\text { Hypothesis Tests About Expected Number of Total Fines } \\
\text { (Using the Fine Probability Model in Table 3) }\end{array}$ & $\chi^{\mathbf{2}(1)}$ & $\boldsymbol{p}$ \\
\hline $\begin{array}{l}\text { 4a. DI (undisclosed + disclosed })<\text { CE } \\
101 *(\text { Constant }+ \text { DI })+79 *(\text { Constant }+ \text { DI }+ \text { DisclosedxDI })\end{array}$ & 33.7 & 0.00 \\
$=180^{*}($ Constant $)$ & 87.6 & 0.00 \\
\hline $\begin{array}{l}\text { 4b. CDI (undisclosed + disclosed })<\text { CE } \\
\quad 180^{*}(\text { Constant }+ \text { CDI })+94 *(\text { Constant })\end{array}$ & \\
\hline
\end{tabular}

\begin{tabular}{|c|c|c|}
\hline $\begin{array}{l}\text { Hypothesis Tests About Expected Number of Fines for Undisclosed } \\
\text { Accidents } \\
\text { (Using the Fine Probability Model in Table 3) }\end{array}$ & $\chi^{2}(1)$ & $p$ \\
\hline $\begin{array}{l}\text { 5a. DI (undisclosed })<\mathrm{CE} \\
\quad \begin{array}{l}101 *(\text { Constant }+\mathrm{DI}) \\
=180 *(\text { Constant })\end{array}\end{array}$ & 89.3 & 0.00 \\
\hline $\begin{array}{l}\text { 5b. CDI (undisclosed })<\mathrm{CE} \\
\quad 86^{*}(\text { Constant }+\mathrm{CDI}) \\
=180^{*}(\text { Constant })\end{array}$ & 137.5 & 0.00 \\
\hline
\end{tabular}

